\title{
Research of Bioactive Chemical Markers in Trunk Bark Extracts of Anogeissus leiocarpa, a Traditional Herbal Remedy for Hypertension
}

\author{
Benjamin Ouedraogo ${ }^{1,2}$, Jules Yoda ${ }^{1}$, Felix Kini ${ }^{1,2, ~ *, ~ J e a n ~ C l a u d e ~ O u e d r a o g o ~}{ }^{2}$, Marius Lompo ${ }^{1}$, \\ Sylvin Ouedraogo ${ }^{1}$ \\ ${ }^{1}$ Department of Medicine, Traditional Pharmacopeia and Pharmacy (Mephatra/Ph), Research Institute for Health Sciences (IRSS), \\ Ouagadougou, Burkina Faso \\ ${ }^{2}$ Laboratory of Environmental Analytical Chemistry and Bioorganic (Lcaebio), Joseph Ki-zerbo University, Ouagadougou, Burkina Faso
}

\author{
Email address: \\ phyto00123@yahoo.fr (F. Kini) \\ ${ }^{*}$ Corresponding author
}

\section{To cite this article:}

Benjamin Ouedraogo, Jules Yoda, Felix Kini, Jean Claude Ouedraogo, Marius Lompo, Sylvin Ouedraogo. Research of Bioactive Chemical Markers in Trunk Bark Extracts of Anogeissus leiocarpa, a Traditional Herbal Remedy for Hypertension. American Journal of Applied Chemistry. Vol. 8, No. 1, 2020, pp. 6-12. doi: 10.11648/j.ajac.20200801.12

Received: January 21, 2020; Accepted: February 10, 2020; Published: February 18, 2020

\begin{abstract}
High blood pressure or hypertension is a public health problem in Burkina Faso. According to official statistics, its prevalence rate is estimated at $20 \%$. The management of this disease is long-term with chronic treatments. This leads the population to resort to efficient, accessible and cheaper herbal medicines. Anogeissus leiocarpa is one of the plants used in traditional medicine for the treatment of hypertension in Burkina Faso. Earlier preclinical studies have proved the efficacy and safety of trunk bark extract. In this investigation, bioactive chemical marker phytocompounds are sought for the development, quality control and standardization of the antihypertensive drug based on this plant. The extracts of this plant are prepared by decoction from trunk bark powder and then fractionated successively with solvents in order of increasing polarity (n-hexane, dichloromethane, ethyl acetate and 1-butanol). The fractions obtained are subjected to phytochemical screening. The antioxidant properties of the different extracts have also been studied since the chemical species known as free radicals, which cause oxidative stress, are related to hypertension. The evaluation of the contents of total phenolic compounds and total flavonoids, which would have antihypertensive properties, was carried out according to the method using Folin-Ciocalteu. The highest total phenolic and total flavonoid contents were obtained with the ethyl acetate fraction $(89.52 \mathrm{mg}$ tannic acid equivalent/g dry extract and $70.87 \mathrm{mg}$ quercetin equivalent/g dry extract for flavonoids). The best antioxidant power is also obtained with the ethyl acetate fraction (IC50: $6.93 \mu \mathrm{g} / \mathrm{mL}$ ). Standardization tests using analytical methods have identified three compounds A, B and C whose structure determination is in progress. These compounds could be used as markers for quality control of the prototype antihypertensive phytodrugs developed.
\end{abstract}

Keywords: Anogeissus leiocarpa, Chemical Markers, Total Polyphenols, Total Flavonoids, Antioxidant Activity, HLC Profile

\section{Introduction}

The use of herbal medicines for primary care is central to the global health system. In developing countries, it meets both economic and socio-cultural requirements. It is estimated that more than $80 \%$ of the world's population now depends on medicinal plants for primary health care $[1,2]$. In addition, many people prefer phytotherapy to pharmaceuticals or a combination of both for the treatment of long-term diseases [3-5]. Hypertension is one of these diseases that is constantly increasing in many countries. In Burkina Faso, this disease has become a public health problem with a prevalence of $20 \%$ [6]. It represents the major risk of cardiovascular disease and cerebrovascular accidents [7, 8]. Hypertension causes serious damage to vital organs such as the brain, kidneys, heart, etc., and thus reduces life 
expectancy. It is now widely accepted that highly reactive chemical species known as free radicals appear to be one of the major causes of this disease [9]. Since the treatment is long-term, in low-income countries most patients prefer herbal therapy. It is within this framework that pharmaceutical drugs are generally substituted by accessible recipes of traditional medicine whose effectiveness and safety of use have been proven. The efficacy of plants in treating hypertension is confirmed in many experimental studies $[2,3,10]$. Nowadays, several plant species are used in the treatment of various diseases including hypertension. Thus, among the medicinal plants used in the treatment of hypertension by traditional health practitioners in Burkina Faso, we find Anogeissus leiocarpa. Anogeissus leiocarpa (Combretaceae), is an evergreen tree widely distributed in Africa $[2,11]$. This plant is well known in traditional African medicine to treat many diseases, mainly skin diseases, hepatitis, hypertension, haemorrhoids, respiratory diseases, headaches, etc. [12-16]. It has also shown strong antiradical and antibacterial activity, antifungal activity against pathogenic microorganisms [17-20]. Antiradical activity could therefore explain the use of this plant in the traditional treatment of hypertension. The general objective of this study is to identify the fraction containing bioactive compounds, to evaluate the content of phenolic compounds, in particular flavonoids, as chemicals with antihypertensive potential and to identify compounds that can be isolated. The compounds identified will be studied in depth in order to elucidate their chemical structure for the quality control and standardization of the Phytomedicine prototype.

\section{Materials and Methods}

\subsection{Plant Material}

The plant material consists of trunk bark of Anogeissus leiocarpa (Combretacaea). The harvested plant material was identified by the Laboratory of Ecology of the University Joseph Ki-Zerbo. The collected bark was dried and then powdered. This powder was used for this study.

\subsection{Methods}

\subsubsection{Moisture Content}

A powder sample $\mathrm{Po}(\mathrm{Po}=1 \mathrm{~g})$ in a the crucible is dried in an oven set at $105{ }^{\circ} \mathrm{C}$ for 3 hours. After cooling in a desiccator, weigh the dry test sample and note the mass $\mathrm{P}$ obtained. The drying process is repeated until the moisture content attained a constant value [21].

\subsubsection{Extraction Methods}

The decoction: $50 \mathrm{~g}$ of vegetable powder was dispersed in $500 \mathrm{ml}$ of distilled water. This was macerated for 15 minutes and then brought to the boil for 30 minutes. After cooling, the mixture is filtered. The filtrate obtained was centrifuged at $2000 \mathrm{rpm}$ for 10 minutes. The supernatant obtained was lyophilised and stored for later analysis. For the tests, a liquid-liquid fractionation was performed: $2 \mathrm{~g}$ of the lyophilized extract was dissolved in $40 \mathrm{ml}$ of distilled water. Using a separating funnel, successive runs were made with solvents of increasing polarity (hexane, dichloromethane, ethyl acetate and butanol).

\subsubsection{Phytochemical Screening}

Phytochemical screening was carried out on chromatoplaques (60 F254, glass support 5 x $10 \mathrm{~cm}$, Fluka Silica gel) according to the methods described in the literature $[19,22,23]$. Each dry extract is solubilized in its extraction solvent at concentration of $10 \mathrm{mg} / \mathrm{mL}$ and $5 \mu \mathrm{L}$ is deposited on the Thin Layer Chromatography plate. The different chromatograms have been developed in the following solvent systems (Table 1).

Table 1. Solvent system used per extract.

\begin{tabular}{ll}
\hline Extracts & Solvent system (V/V/V) \\
\hline Hexane & Hexane- ethyl-methanol acetate (7-2-1) \\
Dichloromethane & Toluene ethyl acetate acetic acid (5-4-1) \\
Ethyl acetate & Ethyl acetate - methanol - water (7-2-1) \\
Butanol & Ethyl acetate - methanol - water (7-2-1) \\
\hline
\end{tabular}

\subsubsection{Total Phenolics Content}

Total phenolic content were determined by Singleton method [24]. These compounds react with the Folin Ciocalteu reagent (FCR) in an alkaline medium. The loss of a phenolic proton in an alkaline medium leads to a phenolate anion that is capable to reducing. the FCR in molybdate forming a blue colored molybdenum oxide complex with a maximum absorption at $760 \mathrm{~nm}$. The intensity of the blue coloration is proportional to the amount of total phenolics present in the test sample. The reaction mixture consisted of $1 \mathrm{ml}$ extract, $1 \mathrm{ml} 2 \mathrm{~N} \mathrm{FCR}$ and $3 \mathrm{ml} \mathrm{20 \%}$ sodium carbonate solution. It was left at rest at room temperature for $40 \mathrm{~min}$ and then the absorbance is measured at $760 \mathrm{~nm}$ on the spectrophotometer (Agilent 8453). In the white control tube, the extract was replaced by distilled water. A standard curve will be drawn with tannic acid $(1-5 \mu \mathrm{g} / \mathrm{ml})$. The tests were carried out in triplicate. The total phenolic concentration of the extract was provided by the formula (1):

$$
\mathrm{Tp}_{\mathrm{T}}=\left(\mathrm{C}_{\text {tube }} \mathrm{x} \mathrm{D}\right) / \mathrm{C}_{\mathrm{i}}
$$

$\mathrm{T}_{\mathrm{PT}}$ is the total phenolic content of the extract expressed as tannic acid equivalent (TEA)/g; $\mathrm{C}_{\text {Tube }}$ is the concentration in $\mathrm{mg} \mathrm{TEA} / \mathrm{ml}$ in the assay tube; $\mathrm{D}$ the dilution factor and $\mathrm{Ci}$ the concentration in $\mathrm{mg} / \mathrm{ml}$ in the stock solution.

\subsubsection{Total Flavonoids Content}

The flavonoid assay was performed using the Kumaran method [25] adapted by Abdel-Hameed [26]. $2 \mathrm{ml}$ of extract of concentration $1 \mathrm{mg} / \mathrm{ml}$ in methanol were mixed with $2 \mathrm{ml}$ of $2 \%$ aluminium trichloride in methanol. After 40 minutes, the absorbance was measured at $415 \mathrm{~nm}$ using the spectrophotometer (Agilent 8453). The white control tube holds $2 \mathrm{ml}$ of methanol. A calibration curve has been drawn using a series of standard solution of quercetin. The tests were carried out in triplicate. The amount of flavonoids in the plant extract as quercetin equivalent (EQ) was determined 
according to the following formula (2):

$$
\mathrm{T}_{\text {Flav }}=\left(\mathrm{A} \cdot \mathrm{m}_{0}\right) /\left(\mathrm{A}_{0} \cdot \mathrm{m}\right)
$$

With $\mathrm{T}_{\text {Flav }}$ the flavonoid content of the extract expressed in $\mathrm{mg}$ EQ $/ \mathrm{mg}$; A the absorbance of the extract; $\mathrm{A}_{0}$ the absorbance of quercetin, $\mathrm{m}$ the mass of the extract in $\mathrm{mg}$ and $\mathrm{m}_{0}$ the mass of quercetin in $\mathrm{mg}$.

\section{Antioxidant Properties}

\subsection{Determination of Antiradical Properties}

The technique used to determine the antiradical activity of extracts is based on the methodology developed by Takao with slight modifications [27]. 1, 1-diphenyl-2picrylhydrazyl (DPPH), the reference oxidant, is dissolved in methanol at a concentration of $2 \mathrm{mg} / \mathrm{mL}$ and used to spray TLC plates after migration.

\subsection{Evaluation of Antioxidant Activity}

$\mathrm{DPPH}^{\bullet}$ free radical scavenging of ethanolic extracts was evaluated using method of Kim et al. [28]. $20 \mu \mathrm{L}$ of different concentrations of ethanol extracts or reference (Trolox) were mixed with $200 \mu \mathrm{L}$ of a methanolic DPPH solution $(0.08$ $\mathrm{mg} / \mathrm{mL}$ ) in a 96 -well microtiter plate. The absorbance was recorded at $490 \mathrm{~nm}$ with spectrophotometer BioRad model 680 , after 30 minutes incubation at room temperature. Each determination was carried out in triplicate.

\section{Isolation Tests of Chemical Markers from the Bioactive Extract}

\subsection{Bioactive Extracts Analysis by Column Chromatography $(\mathrm{CC})$}

The column $(\phi: 2.5 \mathrm{~cm}$ and L: $55 \mathrm{~cm})$ was filled to a height of $20 \mathrm{~cm}$ with silica added to the elution solvent. After degassing, the extract to be fractionated was placed above the silica to a thickness of $1 \mathrm{~cm}$. The extract was eluted with an isocratic solvent system composed of ethyl acetate methanol - water. $20 \mathrm{~mL}$ volumes of eluent were collected in a series of twelve Erlenmeyer. A thin layer chromatography was performed with the contents of the different Erlenmeyer.

\subsection{Bioactive Extracts Analysis by Thin Layer Preparatory Chromatography}

This method is used to isolate the main components identified (markers) by TLC in our extract using glass chromatography plates $(2 \mathrm{~mm}$ silica gel). The sample was solubilized in its extraction solvent. The plate was developed in a saturated vessel containing the appropriate solvent system. The silica containing the compound of interest was then recovered using a spatula. The silica was then dispersed in a small amount of solvent and filtered under a rotavaporizer to allow recovery of the compound.

\subsection{Bioactive Extracts Analysis by HPLC-DAD}

Phenolic compounds are mainly separated by HPLC-DAD. The stationary phases usually used for the separation of phenolic compounds are silica columns grafted with $\mathrm{C} 18$ chains [29]. Separation can be performed in isocratic mode or in elution gradient mode, however the wide range of polarity of these molecules often requires working in elution gradient to avoid co-elections and to elute all compounds. The solvent systems are then composed of water $\left(\mathrm{H}_{2} \mathrm{O}\right)$ and an organic modifier methanol $(\mathrm{MeOH})$ or acetonitrile $(\mathrm{ACN})$. The mobile phase is often acidified at a $\mathrm{pH}$ between 2 and 4, in order to avoid ionization of the many hydroxyl groups of phenolic compounds during analysis, which simultaneously improves resolution and reproducibility [30-31]. Based on these generalities, the chromatographic method was optimized from a crude extract with the objective of visualizing a maximum of the extracted molecules at the characteristic wavelengths of phenolic compounds (254, 279 and $366 \mathrm{~nm}$ ). The method developed is a gradient consisting of ultra-pure $\mathrm{H}_{2} \mathrm{O}$ and $\mathrm{MeOH}$, both acidified to $1 \%$ acetic acid $\left(\mathrm{CH}_{3} \mathrm{COOH}\right)$, the proportions of which are summarized in the table (Table 2). Separation was performed at $1 \mathrm{~mL} / \mathrm{min}$ and $25^{\circ} \mathrm{C}$ on a C18 Alltima column $(250 \times 4.6 \mathrm{~mm} \mathrm{ID,} 5 \mu \mathrm{m})$ by injecting $20 \mu \mathrm{L}$ of extract.

Table 2. HPLC analysis gradient conditions.

\begin{tabular}{lll}
\hline \multirow{2}{*}{ Time (min) } & $\begin{array}{l}\text { \% Solvent } \mathrm{A}\left(\mathrm{H}_{2} \mathrm{O} \mathbf{1 \%}\right. \\
\left.\mathrm{CH}_{3} \mathrm{COOH}\right)\end{array}$ & $\begin{array}{l}\text { \%Solvent B }(\mathrm{MeOH} \\
\left.\mathrm{CH}_{3} \mathbf{C O O H}\right)\end{array}$ \\
\hline 0 & 95 & 5 \\
5 & 95 & 5 \\
10 & 80 & 20 \\
15 & 80 & 20 \\
25 & 50 & 50 \\
30 & 50 & 50 \\
40 & 20 & 80 \\
45 & 20 & 80 \\
46 & 95 & 5 \\
\hline
\end{tabular}

\section{Results and Discussions}

\subsection{Extraction Yield and Moisture Content}

The residual moisture content was $(5.64 \pm 0.90) \%$. The different extraction operations of the plant material gave variable yields depending on the polarity of the extraction solvents and are recorded in the table below (table 3 ):

Table 3. The yields of the liquid-liquid fractionation of the aqueous decoction.

\begin{tabular}{lc}
\hline Extracts & Yield (\%) \\
\hline Hexane & $0,90 \pm 0,10$ \\
Dichloromethane & $4,50 \pm 0,06$ \\
Ethyl acetate & $1,35 \pm 0,02$ \\
Butanol & $16,5 \pm 0,12$ \\
\hline
\end{tabular}

The residual moisture content allowed in a herbal powder for proper storage should not exceed $10 \%$ [19]. The value found in the case of our raw material is $5.64 \pm 0.90$ which is less than $10 \%$. This proves that the herbal medicine could be 
stored for a determined period of time with less risk of contamination and/or alteration of the chemical constituents. The best extraction yield from solvent fractionation are obtained with butanol $16,5 \pm 0,12$. Solvents such as nhexane, dichloromethane and ethyl acetate represent the lowest extraction yields $(<5 \%)$.

\subsection{Phytochemical Screening}

The lyophilized aqueous extract have been characterized by TLC in order to highlight the chemical interest groups. The results obtained are recorded in the following table (Table 4).

Table 4. Results of the chemical screening of lyophilized aqueous extract.

\begin{tabular}{|c|c|c|c|c|c|c|c|c|}
\hline \multirow{2}{*}{$\begin{array}{l}\text { Extracts of Anogeissus } \\
\text { leiocarpa }\end{array}$} & \multicolumn{8}{|c|}{ Groupes chimiques } \\
\hline & Flavonoids & Tannins & Sterols & Triterpenes & Alkaloids & Coumarins & Saponins & Anthocyanins \\
\hline lyophilized aqueous extract & + & + & + & + & - & + & + & + \\
\hline
\end{tabular}

+: presence; -: absence

Phytochemical screening revealed the presence of chemical interest groups in the aqueous extract, namely tannins, flavonoids, saponosides, anthocyanins, sterols and triterpenes and coumarins. Specifically, the presence of phenolic compounds was more observed in the butanol and ethyl acetate fractions. Previous work on trunk bark extracts has also shown the presence of these different phytocompounds. [19, 22]. According to the results obtained, these fractions would be interesting for the evaluation of antioxidant activities and the determination of the content of flavonoids and phenolic compounds.

\subsection{Total Phenolics and Total Flavonoids Content}

The aqueous decoction extract, ethyl acetate extract and butanol extract were used to evaluate the content of phenolic compounds via the different calibration curves (Figures 1,2). The results obtained are shown in the following table (table 5).

Table 5. Results of total phenolic ( $m g$ EAT/g) and total flavonoid ( $m g E Q / g$ ) assays.

\begin{tabular}{lll}
\hline Extracts & Total Phenolics & Total Flavonoids \\
\hline Aqueous decocted & $79,28 \pm 1,38$ & $26,14 \pm 1,66$ \\
Ethyl acetate & $89,52 \pm 0,94$ & $70,87 \pm 1,13$ \\
Butanol & $58,13 \pm 0,51$ & $16,60 \pm 0,60$ \\
\hline
\end{tabular}

The highest concentrations of total phenols $(89.52 \pm 0.94)$ and total flavonoids $(70.87 \pm 1.13)$ are obtained with the ethyl acetate fraction. This selective extract contains quantitatively more phenolic compounds, especially flavonoids, than the other extracts.

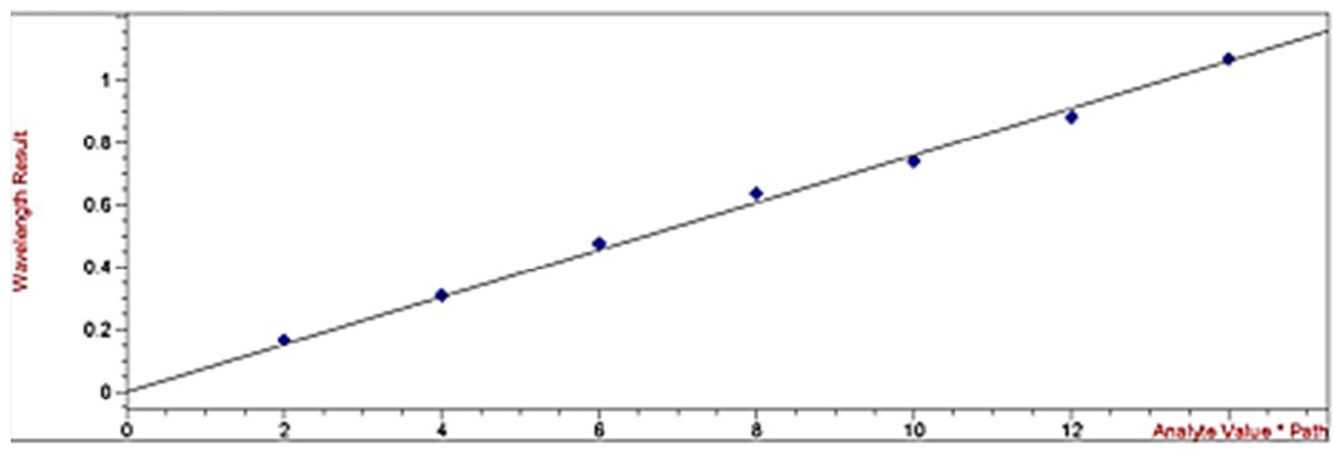

Correlation coefficient: 0.99914

Calibration equation : Conc. $=13.20400 \mathrm{pg} / \mathrm{mL}$. Abs

Figure 1. Calibration curve of a series of standard solution of tannic acid in total phenolic content assay.

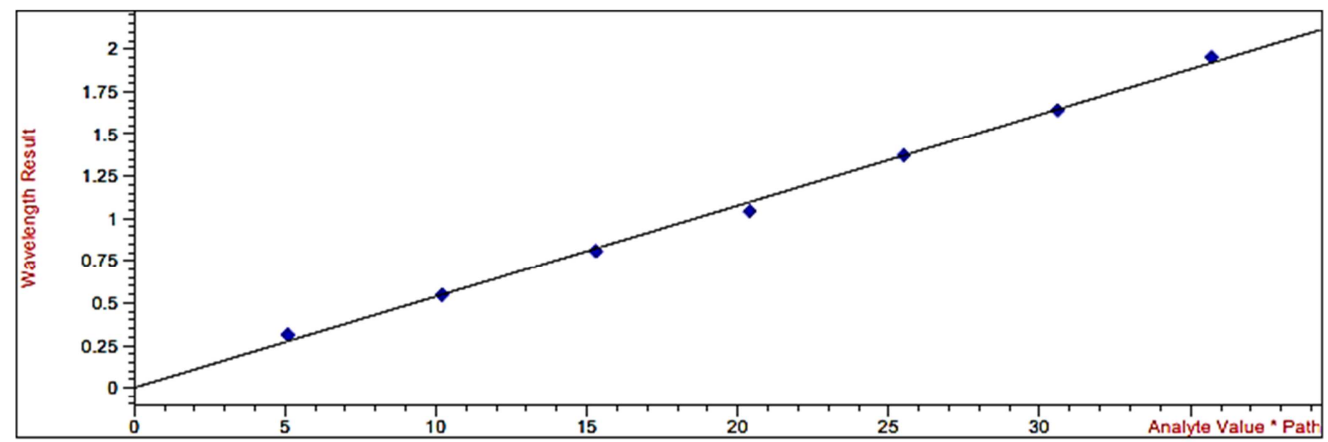

Correlation coefficient: $\quad 0.99944$

Calibration equation : Conc. $=18.58600 \mu \mathrm{g} / \mathrm{mL}$ * A.bs

Figure 2. Calibration curve of a series of standard solution of quercetin in total flavonoids content assay. 


\subsection{Antioxidant Properties}

\subsubsection{Antiradicalaire Activity by TLC}

The correspondence between the active areas and the phytocompounds responsible for this activity was established by analysis of the pulverized TLC plate with the specific reagent (Figure 3). Indeed, the antiradical activity is more pronounced in ethyl acetate and butanol extracts, compared to hexane and dichloromethane extracts; this could be explained by the richness in phenolic compounds of acetate and butanol extracts.

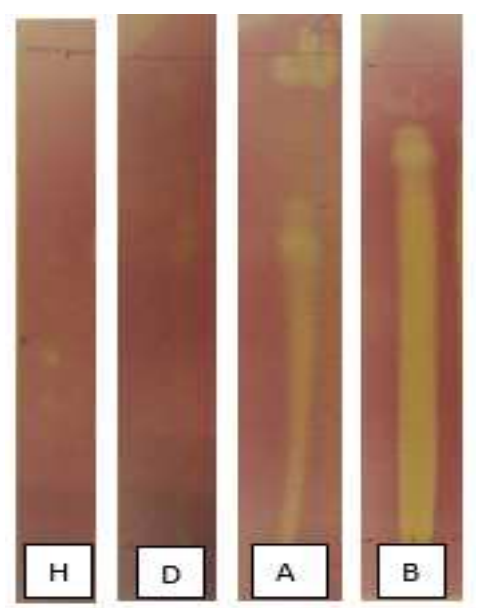

H: hexane, D: dicloromethane, A: ethyl acetate, B: butanol

Figure 3. Anti-radical activity of the different fractions.

\subsubsection{Evaluation of Antioxidant Activity}

The inhibitory concentration 50 (IC50), i.e. the concentration of the extract likely to cause $50 \%$ inhibition of our extracts, has been determined and the results are shown in the table (Table 6).
Table 6. Results antioxidant activities of extracts.

\begin{tabular}{ll}
\hline Extracts & IC50 $(\boldsymbol{\mu g} / \mathbf{m L})$ \\
\hline Aqueous decoction & $7,56 \pm 0,2$ \\
Ethyl acetate extract & $6,92 \pm 1,06$ \\
1-Butanol extract & $7,42 \pm 1,21$ \\
\hline
\end{tabular}

The results obtained show that the different extracts have antioxidant activity. The ethyl acetate extract is the most active with an IC50 (Inhibitory concentration 50) of $6.92 \mu \mathrm{g} / \mathrm{mL}$. This activity could be due to the remarkable presence of phenolic compounds, especially flavonoids in the extract [22].

\subsection{Bioactive Extract Analysis and Isolation tests for Phytocompounds $A, B$ and $C$}

The ethyl acetate fraction was fractionated by silica column chromatography. Elution was carried out with a chloroform-methanol solvent system in the proportions (9-1) that gave six fractions (F1 to F6). TLC monitoring revealed that F2 to F6 had similar profiles (three main spots) and were therefore collected and subjected to separation on preparatory chromatoplates. 3 compounds $\mathrm{A}, \mathrm{B}$ and $\mathrm{C}$ have been isolated (Figure 4).

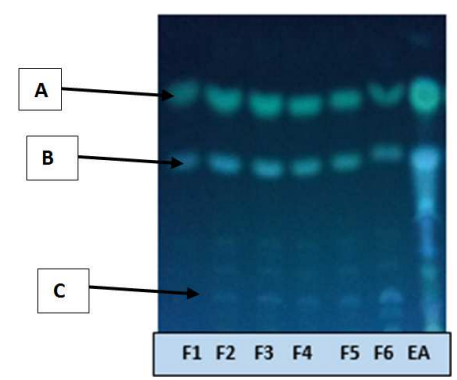

Figure 4. Chromatogram of the ethyl acetate extract (EA) fraction and subfractions F1 to F6

\subsection{Bioactive Extract Analysis by HPLC}

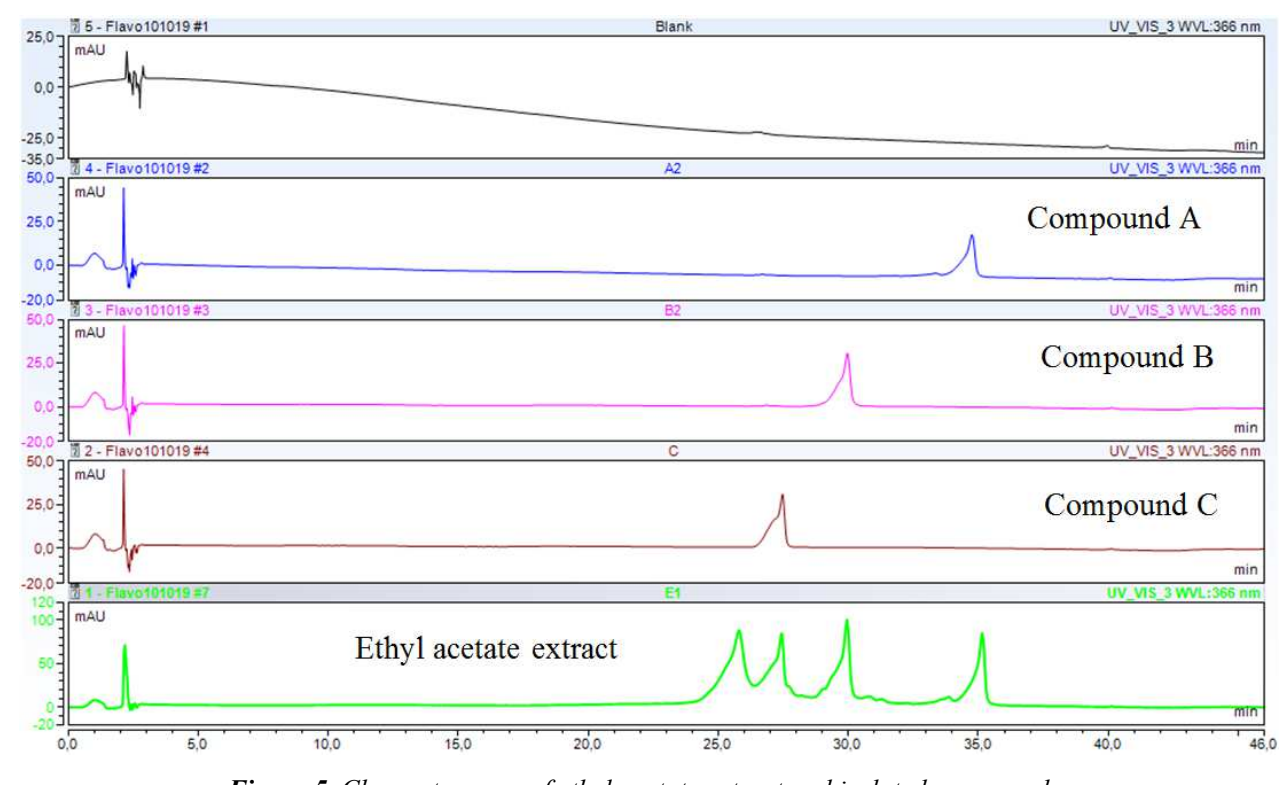

Figure 5. Chromatograms of ethyl acetate extract and isolated compounds. 
The ethyl acetate fraction and the purified fractions containing the isolated compounds were analysed by HPLC (Figure 5). The HPLC profiles of three pure extracts (A, B, C) show for each compound a single peak at distinct retention times A (35,5 min), B $30 \mathrm{~min}), \mathrm{C}$ (27,5 min). These three compounds are easily identifiable in the chromatogram of the ethyl acetate extract at the same retention times. HPLC spectra show the purity state of the compounds. Purification continues to obtain high-purity compounds for structural identification. In a future study, the molecular structure of the three compounds will be elucidated using more advanced analytical methods such as HPLC-MS, IR and NMR spectrometry.

\section{Conclusion}

In this study, we performed several analyses in order to identify the active extract. The phytochemical screening carried out on the various aqueous extracts and on the selective organic extracts indicated the presence of chemical compounds of interest, particularly polyphenols. These compounds in particular flavonoids have an antihypertensive potential. The evaluation of the contents of total polyphenols and total flavonoids of the aqueous extracts and the various organic fractions shows that the ethyl acetate fraction has the best contents of total phenols and total flavonoids. Moreover, the fraction with the ethyl acetate extract also showed the best antioxidant power. The active extract was therefore chosen for the search for chemical markers. The main compounds A, B, C isolated from this extract will be used as markers for quality control and standardisation, after determination of their structure.

\section{Acknowledgements}

The authors is grateful to Research Institute for Health Sciences (IRSS) for its laboratory facilities.

\section{References}

[1] Choudhary N. and Sekhon B. S. An overview of advances in the standardization of herbal drugs. J. Pharm. Educ. Res. 2011, 2 (2): 55-70.

[2] Agaie B. M., Onyeyili P. A., Muhammad B. Y., Landan M. J. Some Toxic Effects of Aqueous Leaf Extract of Anogeissus leiocarpus in rats. Journal of Pharmacology and Toxicology 2007, 2 (4): 396-401.

[3] Bailey C., Day C., Leatherdale B. Traditional treatments for diabetes from Asia and West Indies. Practical Diabetes 1986, 3 (4): 190-4.

[4] Day C., Bailey C. A. Diabetologist's herbal. Med Lit Diabetes Ray Soc. Med 1988, 5: 31-4

[5] Swanston-Flatt S. K., Day C., Bailey C. J., Flatt P. R. Evolution of traditional plant treatments for diabetes: studies on streptozotocin diabetic mice. Acta Diabetol Lat. 1989, 26:
$51-5$

[6] Tougouma S. J.-B., Hien H., Aweh A. B., Yameogo A. A., Meda Z. C., Kambire Y., Millogo G. R., Kinda G., Sidibe S., Ouedraogo M., "Prevalence and knowledge of arterial hypertension in the elderly: Cross-sectional study conducted in bobo-dioulasso, Burkina faso," Pan Afr. Med. J. 2018, 30: 243.

[7] Bonnet D., Aggoun Y. Known cardiovascular risk factors (hypertension, diabetes, hypercholesteremia): secondary and tertiary prevention in pediatric patients. Arch Pediatr. 2002, 9: $131-$

[8] Rigaud A. S., Hanon O., Bouchacourt P., Forette F. Cerebral complications of hypertension in the elderly. Rev Med Interne 2001, 22 (10): 959-968.

[9] Yadeta N. C. Phytochemical Investigation and Antioxidant Activity of Root Extract of Aloe gilbertii Reynolds, from Konso, Southern Ethiopia. American Journal of Applied Chemistry 2019, 7 (5): 130-136.

[10] Belemnaba L., Nitiema M., Ilboudo S., Ouedraogo N., Ouedraogo G. G.; Belemlilga, M. B., Ouedraogo, S., Guissou, I. P. O8 Study on antihypertensive activity of an aqueous extract of Anogeissus leiocarpus (AEAL) DC Guill et Perr bark of trunk in L-NAME-induced hypertensive rats. Biochem. Pharmacol. 2017, 139, 112.

[11] Adejumobi J. A., Ogundiya M. O., Kolapo A., kunade M. B. Phytochemical composition and in vitro antimicrobial activity of Anogeissus leiocarpus on some common oral pathogens. Journal of Medicinal Plants Research 2008; 2 (8): 193-196.

[12] Okpekon T., Yolou S., Gleye C., Roblot F., Loiseau P., Bories C. et al. Antiparasitic activities of medicinal plants used in Ivory Coast. Journal of Ethnopharmacology. 2004, 90: 91-97.

[13] Vonthron-Senecheau C., Weniger B., Ouattara M., Tra Bi F., Kamenan A., Lobstein A. et al. In vitro antiplasmodial activity and cytotoxicity of ethnobotanically selected Ivorian plants. Journal of Ethnopharmacology 2003, 87: 221-225.

[14] Mann A, Amupitan J. O., Oyewale A. O., Okogun J. I., Ibrahim K., Oladosu P. et al. Evaluation of in vitro antimycobacterial activity of Nigerian plants used for treatment of respiratory diseases. African Journal of Biotechnology. 2008; 7 (11): 1630-1636.

[15] Ademosun A. O., Adebayo, A. A., Oboh G. Anogeissus leiocarpus attenuates paroxetine-induced erectile dysfunction in male rats via enhanced sexual behavior, nitric oxide level and antioxidant status. Biomed. Pharmacother. 2019, 111, $1029-1035$.

[16] Olugbami J. O., Damoiseaux R., France B., Onibiyo E. M., Gbadegesin M. A., Sharma S., Gimzewski J. K. and Odunola O. A. A comparative assessment of antiproliferative properties of resveratrol and ethanol leaf extract of Anogeissus leiocarpus (DC) Guill and Perr against HepG2 hepatocarcinoma cells. BMC Complementary and Alternative Medicine 2017, 17: 381.

[17] Mann A., Banso A., Clifford L. C. An antifungal property of crude plant extracts from Anogessius leiocarpus and Terminalia avicennioides. Tanzania Journal of Health Research. 2008, 10 (1): 34-38. 
[18] Adigun JO, Amupitan JO, Kelly DR. Isolation and investigation of antimicrobial effect of 3, 4, 3'- tri Omethylflavellagic acid and its glucoside from Anogeissus leiocarpus. Bull. Chem. Soc. Ethiopia, 2000; 14 (2): 169- 174.

[19] Ouedraogo B., J. Yoda, F. B. Kini, M. Koala, and Y. Bonzicoulibaly, "phytochemical screening and in vitro antioxidant study of six plants used for the treatment of hypertension in traditional medicine," World J. Pharm. Pharm. Sci. 20198 (4) $1665-1678$

[20] Salih E. Y. A., Kanninen M., Sipi M., Luukkanen O., Hiltunen R., Vuorela H., Julkunen-Tiitto R., Fyhrquist P. Tannins, flavonoids and stilbenes in extracts of African savanna woodland trees Terminalia brownii, Terminalia laxiflora and Anogeissus leiocarpus showing promising antibacterial potential. S. Afr. J. Bot. 2017, 108, 370-386.

[21] Kassahun A., Feleke G. Chemical Composition and PhysicoChemical Analysis of Eucalyptus Globulus Leave and Oil. Science Journal of Chemistry 2019, 7 (2): 36-38.

[22] Orlando G., Ferrante C., Zengin G., Sinan K. I., Bene K., Diuzheva A., Jeko J, Cziáky Z., Di Simone S., Recinella L., Chiavaroli A., Leone S., Brunetti L., Picot-Allain C. M. N., Mahomoodally M. F., * and Menghini L. Qualitative Chemical Characterization and Multidirectional Biological Investigation of Leaves and Bark Extracts of Anogeissus leiocarpus (DC.) Guill. \& Perr. (Combretaceae). Antioxidants 2019, 8, 343.

[23] Bekro Y. A., Bekro M. J. A., Boua B. B., Tra Bi F. H. \& Ehile E. E. Ethnobotanical study and phytochemical screening of Caesalpinia benthamiana (Baill.) Herend. And Zarucchi (Caesalpiniaceae). Sciences et Nature 2007, 4: 217-225.
[24] Singleton V. L., Orthofer R., Lamuela-Raventos R. M. Analysis of total phenols and other oxidation substrates and antioxidants by means of Folin-Ciocalteu reagent. Methods in enzymology 1999, 299: 152-78.

[25] Kumaran A., Karunakaran R. J. In vitro antioxidant activities of methanol extracts of five Phyllanthus species from India. LWT - Food Science and Technology 2007, 40 (2): 344-52.

[26] Abdel-Hameed E-SS. Total phenolic contents and free radical scavenging activity of certain Egyptian Ficus species leaf samples. Food Chemistry 2009; 114 (4): 1271-7.

[27] Takao T., Kitatami F., Watanabe N., Yagi A. \& Sakata K. A simple screening method for antioxydants and isolation of several antioxydants produced by marine bacteria from fish and shell fish. Bioscience, Biotechnology and Biochemistry 1994 58: 1780-1783.

[28] Kim K. S., Lee S., Lee Y. S., Jung S. H., Park Y., Shin K. H. and Kim B. K. Anti-oxidant activities of the extracts from the herbs of Artemisia apiacea. Journal of Ethnopharmacology 2003, 85: 69-72.

[29] Robards, K. and Antolovich, M. Analytical chemistry of fruit bioflavonoids A review. Analyst. 1997, 122 (2), 11R-34R.

[30] De Rijke E., Out P., Niessen W. M. A., Ariese F., Gooijer C. and Brinkman, U. A. T. Analytical separation and detection methods for flavonoids. Journal of Chromatography A 2006, 1112 (1-2), 31-63.

[31] Stalikas C. D. Extraction, separation, and detection methods for phenolic acids and flavonoids. Journal of Separation Science 2007, 30 (18): 3268-3295. 